\title{
Sustainable development through desert tourism planning: a SWOT approach
}

\author{
M. Sabokkhiz \& S. Sabokkhiz \\ University of Isfahan, College of Engineering, \\ Department of Surveying and Geomatics Engineering, Iran
}

\begin{abstract}
In this paper a new method is presented for sustainable development in desert regions using their tourism potentials. By providing job opportunities, tourism can play an important role in sustainable development in developing countries. Desert areas are characterized by a low and sparse population spread over large areas of lower productivity land which made their sustainable development complex. Deserts have a variety of potentials from a tourism point of view in which comprehensive planning can lead them to a sustainable development. Iran, located on the world desert girdle, contains $3.8 \%$ of the world's deserts. Lack of natural resources in Iran desert lands makes their development very slow and unsustainable. Research and practices in other countries such as Australia showed that tourism planning can be viewed as one of the most appropriate ways for sustainable development in such areas. Previous research has focused on tourism development by using the deserts' environmental characteristics and they mostly neglect sustainability in development. This research intends to provide sustainability through tourism planning in desert environments in Iran. We firstly investigate tourism's interesting parameters in Iran's desert lands. Then, by using AHP analysis and comparing different rural areas from these parameters' point of view the best region for starting desert tourism planning is selected. The best area is Mesr Village near the central desert of Iran. Afterward, using SWOT and investigating strengths, weaknesses, opportunities and threats, some strategic plans for developing the tourism industry and subsequently sustainable development in this area are proposed.
\end{abstract}

Keywords: AHP model, SWOT model, tourism planning, desert tourism. 


\section{Introduction}

In the world there are attractive desert areas distributed upon their geographical locations which have their own conditions. For instance Arabian, Australian, Iranian, the Sahara, North American, Indian, China deserts ... [7]; research based on the effect of tourism on regional deserts. By increasing tourists in these areas and creating job through the appropriate planning we can reach better productivities. In this research, first by using AHP method with pairwise comparison, tourism attractions were identified and given rank. Then all attractions have been evaluated individually as a case study on desert villages in central Iran desert, specifically Mesr desert and each village got its point in each attraction. At the end, the chosen village has been selected from the total points. Second, in order to appropriate planning for the selected village, the method of SWOT used and helping from points of strength and weakness, opportunity and threat reach exact targets and executive policies. This plan evaluated according to the potential of the regional nature in order to develop the economy.

\section{Method and modelling}

In this section we explain the methods for development in desert villages to get a better result. Therefore, by determining desert attractions, a village is selected for planning. In this stage we obtain the right choice of desert tourism planning by using the method of AHP to get marking for important criteria in desert tourism with Expert Choice[4] and calculating the value of each criteria and their impact on regional villages. The next stage is for developing the true planning by providing the table of SWOT from Mesr desert offering alternatives and policies.

\subsection{The AHP method}

AHP, developed by [11], addresses how to determine the relative importance of a set of activities in a multi-criteria decision problem. The process makes it possible to incorporate judgments on intangible qualitative criteria alongside tangible quantitative criteria [2]. Structure of the model; comparative judgment of the alternatives and the criteria; synthesis of the priorities are the bases of the AHP method. In the literature, AHP, has been widely used in solving many complicated decision-making problems [3]. In the first step, a complex decision problem is structured as a hierarchy. AHP initially breaks down a complex multicriteria decision-making problem into a hierarchy of interrelated decision criteria, decision alternatives. With the AHP, the objectives, criteria and alternatives are arranged in a hierarchical structure similar to a family tree. The overall goal of the problem at the top, multiple criteria that define alternatives in the middle, and decision alternatives at the bottom which has three levels of a hierarchy. The second step is the comparison of the alternatives and the criteria. Once the problem has been decomposed and the hierarchy is constructed, prioritization procedure starts in order to determine the relative importance of the criteria within each level. The pairwise judgment starts from the second level and 
finishes in the lowest level alternatives. In each level, the criteria are compared pairwise according to their levels of influence and based on the specified criteria in the higher level [1]. In AHP, multiple pairwise comparisons are based on a standardized comparison scale of nine levels (Table 1).

Table 1: $\quad$ Standardized comparison scale of nine levels.

\begin{tabular}{cc}
\hline \multicolumn{2}{c}{ Nine-point intensity important scale [9] } \\
\hline Definition & Definition Intensity of importance \\
\hline Equally important & 1 \\
Moderately more important & 3 \\
Strongly more important & 5 \\
Very strong more important & 7 \\
Extremely more important & 9 \\
Intermediate more important & $2,4,6,8$ \\
\hline
\end{tabular}

The final consistency ratio, usage of which allows someone to conclude whether the evaluations are sufficiently consistent, is calculated as the ratio and the random index, as indicated [9].

\subsection{SWOT}

SWOT analysis is an important support tool for decision-making, and is commonly used as a means to systematically analyze an organization's internal and external environments [6,8]. By identifying its strengths, weaknesses, opportunities, and threats, the organization can build strategies upon its strengths, eliminate its weaknesses, and exploit its opportunities or use them to counter the threats - identifying the strengths and weaknesses by an internal environment appraisal while the opportunities and threats are identified by an external environment appraisal [10]. SWOT analysis summarizes the most important internal and external factors that may affect the organization's future, which are referred to as strategic factors.

The external and internal environments consist of variables which are outside and inside the organization, respectively. The organization's management has no short-term effect on either type of variable. Comprehensive environmental analysis is important in the recognition of the variety of internal and external forces which an organization is faced with. On the one hand these forces may comprise potential stimulants, and on the other hand, they may consist of potential limitations regarding the performance of the organization or the objectives that the organization wishes to achieve. The obtained information can be systematically represented in a matrix; different combinations of the four factors from the matrix can aid in determination of strategies for long-term progress [5].

When used properly, SWOT can provide a good basis for strategy formulation. However, SWOT analysis is not without weaknesses in the measurement and evaluation steps. In conventional SWOT analysis, the magnitude of the factors is not quantified to determine the effect of each factor 
on the proposed plan or strategy. In other words, SWOT analysis does not provide an analytical means to determine the relative importance of the factors, or the ability to assess the appropriateness of decision alternatives based on these factors. While it does pinpoint the factors in the analysis, individual factors are usually described briefly and very generally. More specifically, SWOT allows analysts to categorize factors as being internal (strengths, weaknesses) or external (opportunities, threats) in relation to a given decision, and thus enables them to compare opportunities and threats with strengths and weaknesses. However, the result of SWOT analysis is often merely a listing or an incomplete qualitative examination of the internal and external factors. For this reason, SWOT analysis cannot comprehensively appraise the strategic decision-making process [12].

\section{Case study}

Mesr village is located in the central desert of Iran including some others which have potential for desert tourism planning with their own spatial aspect such as: Garme, Mesr, Aruosan, Iraj, Biazeh.

To select the best case in desert village tourism planning, we first determine tourism potentials and its applicable plan by using Expert Choice software and analyzing pairwise comparisons in order to evaluate each aspect then, marking each aspect by its priority and the coefficient importance. Afterwards we analyze each attraction in each case thus marking all cases, at the end choosing the most marked village for desert tourism planning.

\subsection{AHP model}

\subsubsection{Identifying attractions and marking}

Select important attractions marking pairwais and evaluating each mark for planning. The following table shows attraction marking

Table 2: $\quad$ Pairwais comparison of desert tourism indicator.

\begin{tabular}{||c|c|c|c|c|c|c|c|c|c||}
\hline \hline C9 & C8 & C7 & C6 & C5 & C4 & C3 & C2 & C1 & Indicator \\
\hline 3 & 3.2 & 2.4 & 5 & 2 & 4.34 & 4.4 & 4.5 & & C1 \\
\hline 3 & 2.6 & 2 & 5 & 2.6 & 3 & 4 & & & C2 \\
\hline $4 / 5$ & 2 & $2 / 6$ & $3 / 2$ & $3 / 3$ & 4 & & & & C3 \\
\hline 3 & 2 & 1 & $5 / 3$ & 3 & & & & & C4 \\
\hline $3 / 2$ & 2 & $4 / 3$ & 5 & & & & & & C5 \\
\hline 2 & $2 / 4$ & 3 & & & & & & & C6 \\
\hline $4 / 3$ & $4 / 5$ & & & & & & & & C7 \\
\hline $4 / 5$ & & & & & & & & & C8 \\
\hline & & & & & & & & & C9 \\
\hline \hline
\end{tabular}


Table 3: $\quad$ Indicator marking based on AHP method.

\begin{tabular}{|l|l|l|}
\hline & Indicator & Rank average \\
\hline C1 & Existence of sand hills & 0.257 \\
\hline C2 & Space of sand hills & 0.175 \\
\hline C3 & Access to main road & 0.156 \\
\hline C4 & Camel riding & 0.094 \\
\hline C5 & Traditional houses for accommodation & 0.107 \\
\hline C6 & Wild life observation & 0.047 \\
\hline C7 & Night sky & 0.080 \\
\hline C8 & Planning of desert sports & 0.053 \\
\hline C9 & Attraction of route images & 0.031 \\
\hline
\end{tabular}

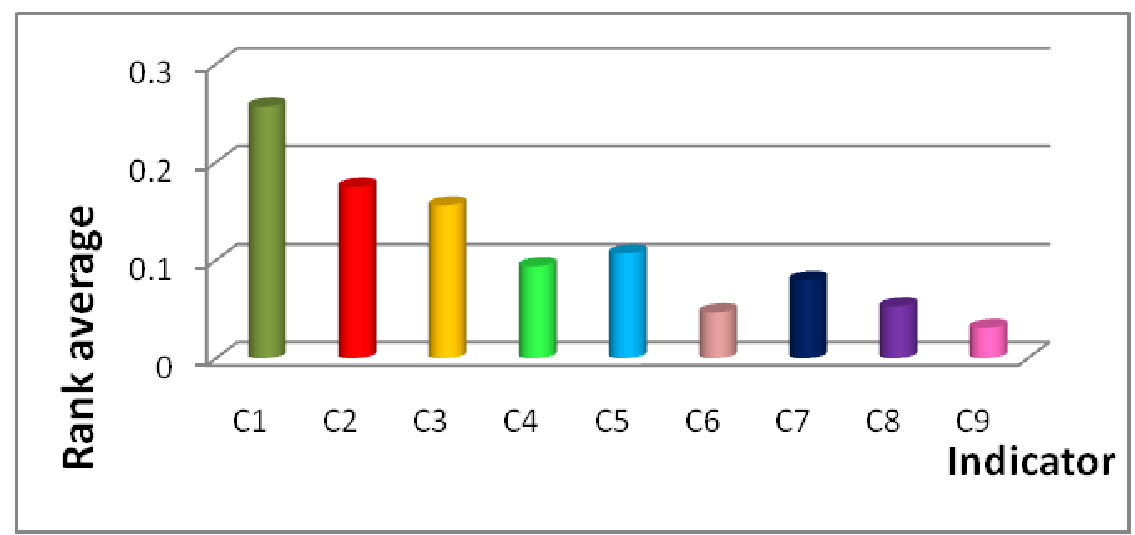

Figure 1: Indicator marking based on AHP method.

\subsubsection{Select better alternative}

In this stage analyzing pairwais villages in relation with any attractions and distinguishing each village mark. Afterwards displaying total results of village marks in Table 4, because of the high volume of data the outcomes are summarised and a better alternative is chosen.

Table 4: $\quad$ Selecting a better choice based on the AHP method.

\begin{tabular}{|c|c|}
\hline Village & Rank average \\
\hline Mesr & 0,500 \\
\hline Garme & 0.204 \\
\hline Aruosan & 0.175 \\
\hline Iraj & 0.064 \\
\hline Biazeh & 0.056 \\
\hline
\end{tabular}




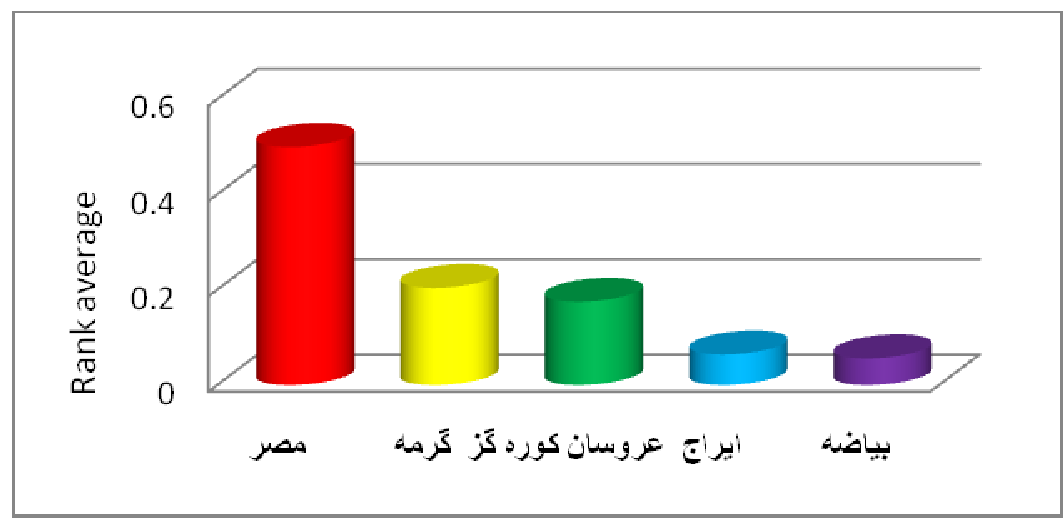

Figure 2: $\quad$ Select better choice based on AHP method.

The following subjects are presented regarding the marks:

1. Based on the marking system, Mesr village got the most potential of desert tourisms and priority for the planning

2. Garme and Aruosan koregaz villages can complete a tourism circle parallel with Mesr village which prevents a tourist revisiting a place.

3. Iraj and Biazeh villages deserve exact planning in order to keeping traditional architecture display, observe night sky and lack of sand hills.

\subsection{SWOT model}

After an exact analysis of the area by SWOT and identifying the present situation and considering appropriate planning for the future of the area, we can conclude that the principle of sustainability is reachable. Therefore providing the SWOT model in light of the importance of the factors and we conclude the following results.

Table 5: $\quad$ SWOT.

\begin{tabular}{|c|c|c|c|}
\hline Strengths & Weaknesses & Opportunity & Threat \\
\hline $\begin{array}{l}\text { - Space of } \\
\text { sand hills } \\
\text { - night sky } \\
\text { - observation } \\
\text { - camel riding } \\
\text { - wild life } \\
\text { - traditional } \\
\text { house } \\
\text { - local foods } \\
\text { - located in } \\
\text { the center of } \\
\text { country }\end{array}$ & $\begin{array}{l}\text { Sand hails } \\
\text { - hot weather } \\
\text { from June to Oct } \\
\text { Lack of facility } \\
\text { for observation } \\
\text { less tourism } \\
\text { agencies } \\
\text { - less } \\
\text { communications }\end{array}$ & $\begin{array}{l}\text { - Possibility of } \\
\text { professional } \\
\text { observation } \\
\text { desert sports } \\
\text { - Traditional houses } \\
\text { for accommodation } \\
\text { job creation } \\
- \text { increase of tourists } \\
\text { creation of } \\
\text { handicraft } \\
\text { economic } \\
\text { development and } \\
\text { rural improvement }\end{array}$ & $\begin{array}{l}\text { Number of } \\
\text { sandstorm days } \\
\text { when tourist } \\
\text { crowded } \\
\text { increase of } \\
\text { tourist compared } \\
\text { to the capacity to } \\
\text { destroy wild life } \\
\text { - losing the } \\
\text { original culture } \\
\text { lack of attention } \\
\text { to desert } \\
\text { architecture }\end{array}$ \\
\hline
\end{tabular}




\section{Conclusion}

After surveys taken in desert tourism planning on a few villages in Iran central desert, the following results have been obtained:

Mesr village had the most potential for desert tourism among all villages in the area. Other villages can make a circle of tourism for the area, in general the complex of the villages can establish an axis of desert tourism alongside each other which has a different appearance in desert tourism spatially in the desert of Iran.

Considering the ability of the environment to accept tourism, the SWOT model can deliver the right use of the area's facilities and coordinated plan. This program supplies the principles of the appropriate desert tourism planning.

\section{References}

[1] Albayrak, E., \& Erensal, Y. C. Using analytic hierarchy process (AHP) to improve human performance. An application of multiple criteria decision making problem. Journal of Intelligent Manufacturing, 15(2004) 491-503

[2] Badri, M. A, A combined AHP-GP model for quality control systems. international Journal of Production Economics, 72(2001) 27-40

[3] Chan, F. T. S, \& Kumar, N. Global supplier development considering risk factors using fuzzy extended AHP-based approach. OMEGA, 35(2007) 417- 431

[4] Expert Choice, Expert Choice, Analytical Hierarchy Process (AHP) Software, Version 9.5, Expert Choice, Pittsburg, 2000

[5] G. Houben, K. Lenie, K. Vanhoof, A knowledge-based SWOT-analysis system as an instrument for strategic planning in small and medium sized enterprises, Decision Support Systems 26 (1999) 125-135

[6] J. Kangas, M. Kurtila, M. Kajanus, A. Kangas, Evaluating the management strategies of a forestland estate-the S-O-S approach, Journal of Environmental Management 69 (2003) 349-358.

[7] Johnson. Mark, The Ultimate Desert Handbook, R.M.P /McGraw-Hill, 2003

[8] M. Kurttila, M. Pesonen, J. Kangas, M. Kajanus, Utilizing the analytic hierarchy process (AHP) in SWOT analysis-a hybrid method and its application to a forest-certification case, Forest Policy and Economics 1 (2000) 41-52.

[9] Pakdin Amiri. Morteza, Project selection for oil-fields development by using the AHP and fuzzy TOPSIS methods, Expert systems with applications (2010) in press.

[10] R.G. Dyson, Strategic development and SWOT analysis at the University of Warwick, European Journal of Operational Research 152 (2004) 631-640

[11] Saaty, T. L. The analytic hierarchy process. New York: McGraw-Hill, (1980). 
366 Sustainable Tourism IV

[12] Yuksel. I, Dagdeviren. M, Using the analytic network process (ANP) in a SWOT analysis - A case study for a textile firm, Information Sciences 177 (2007) 3364-3382 